Article

\title{
Improved Antitumor Efficacy of Combined Vaccine Based on the Induced HUVECs and DC-CT26 Against Colorectal Carcinoma
}

\author{
Qiushuang Zhang ${ }^{1,+}$, Chao Xie ${ }^{1,+}$, Dongyu Wang ${ }^{1}$, Yi Yang ${ }^{1}$, Hangfan Liu ${ }^{1}$, Kangdong Liu ${ }^{1,2}$, \\ Jimin Zhao ${ }^{1,2}$, Xinhuan Chen ${ }^{1,2}$, Xiaoyan Zhang ${ }^{1,2}$, Wanjing Yang ${ }^{1,2}$, Xiang Li ${ }^{1,2}$, Fang Tian ${ }^{1,2}$, \\ Ziming Dong ${ }^{1,2}$ and Jing $\mathrm{Lu}^{1,2, * \mathbb{C}}$ \\ 1 Department of Pathophysiology, School of Basic Medicine, Zhengzhou University, Zhengzhou 450001, \\ Henan, China; zhangqiushuang58@163.com (Q.Z.); xiechao_9966@126.com (C.X.); \\ wdy1028796652@163.com (D.W.); yangyi20086@163.com (Y.Y.); m15249680100@163.com (H.L.); \\ kdliu@zzu.edu.cn (K.L.); zjm.0427@163.com (J.Z.); chen_xinhuan@126.com (X.C.); \\ zhangxiaoyan@zzu.edu.cn (X.Z.); ywj1102@zzu.edu.cn (W.Y.); ninika5009@126.com (X.L.); \\ tianfang418@163.com (F.T.); dongzm@zzu.edu.cn (Z.D.) \\ 2 Collaborative Innovation Center of Henan Province for Cancer Chemoprevention, Zhengzhou 450001, \\ Henan, China \\ * Correspondence: lujing@zzu.edu.cn; Tel.: +86-1361-3810-516 \\ + These authors contributed equally to this manuscript.
}

Received: 24 April 2019; Accepted: 21 May 2019; Published: 22 May 2019

check for updates

\begin{abstract}
Angiogenesis is essential for the development, growth, and metastasis of solid tumors. Vaccination with viable human umbilical vein endothelial cells (HUVECs) has been used for antitumor angiogenesis. However, the limited immune response induced by HUVECs hinders their clinical application. In the present study, we found that HUVECs induced by a tumor microenvironment using the supernatant of murine CT26 colorectal cancer cells exerted a better antiangiogenic effect than HUVECs themselves. The inhibitory effect on tumor growth in the induced HUVEC group was significantly better than that of the HUVEC group, and the induced HUVEC group showed a strong inhibition in CD31-positive microvessel density in the tumor tissues. Moreover, the level of anti-induced HUVEC membrane protein antibody in mouse serum was profoundly higher in the induced HUVEC group than in the HUVEC group. Based on this, the antitumor effect of a vaccine with a combination of induced HUVECs and dendritic cell-loading CT26 antigen (DC-CT26) was evaluated. Notably, the microvessel density of tumor specimens was significantly lower in the combined vaccine group than in the control groups. Furthermore, the spleen index, the killing effect of cytotoxic T lymphocytes (CTLs), and the concentration of interferon- $\gamma$ in the serum were enhanced in the combined vaccine group. Based on these results, the combined vaccine targeting both tumor angiogenesis and tumor cells may be an attractive and effective cancer immunotherapy strategy.
\end{abstract}

Keywords: angiogenesis; human umbilical vein endothelial cell; vaccine; tumor microenvironment; dendritic cell; colorectal carcinoma

\section{Introduction}

Colorectal carcinoma (CRC) is one of the most common and deadly cancers worldwide, and its incidence is on the rise. About 1.09 million new cases were diagnosed, and more than 550,000 people died from the disease in 2018 [1]. Tumor angiogenesis is required for cancer growth and metastasis and has been considered a potential target for CRC treatment [2]. At present, most antiangiogenic drugs, such as synthetic molecules and monoclonal antibodies, have obvious side effects and readily produce 
drug resistance, which limits their clinical application [3]. Currently, immunotherapy of tumors with vaccines is another promising avenue of antiangiogenesis therapy to overcome these drawbacks [4-6].

Recent studies have demonstrated that a human umbilical vein endothelial cell (HUVEC) vaccine could inhibit tumors by initiating antiangiogenic effects with both cellular and humoral immunity [7-10]. Presenting various growth factors during angiogenesis, endothelial cell vaccines may be more effective than targeting one specific antigen in tumor blood vessels. Antitumor effects of endothelial cell vaccines have been demonstrated in preclinical mouse models and clinical trials [7,9-13]. Cultured HUVECs in vitro are proliferative endothelial cells, similar to new vessels with proliferative activity in solid tumors and express some proteins absent or barely detectable in quiescent vascular endothelium [14]. However, the immune response induced by a HUVEC vaccine is limited because HUVECs are still very different from tumor endothelial cells. One of the biggest challenges of using a HUVEC vaccine is how to improve the effectiveness of antitumor therapy. Here, we hypothesized that HUVECs induced by the tumor microenvironment might have characteristics more like tumor vascular endothelial cells than HUVECs, thereby producing a stronger suppressive effect on tumor angiogenesis. To test this hypothesis, we obtained the supernatant of murine CT26 colorectal carcinoma cells to simulate a tumor microenvironment and investigated its influence on HUVECs.

Dendritic cells (DCs) are the most powerful specialized antigen-presenting cells in vivo. These cells can take up tumor antigen and induce cytotoxic T lymphocytes (CTLs) to mediate powerful specific antitumor immune effects [15]. During the last few decades, researchers have achieved inhibitory tumor effects with DCs loaded with tumor-associated antigens, cytokines, chemokines, and other modifications by activating the antitumor immune response [16-20]. By incubating DCs with whole tumor lysates or autologous tumor cells, a higher number of antigens can be obtained, which can express multiple epitopes on MHC class I or II, leading to T and cytotoxic reactions. DCs-based vaccines have shown promising results in terms of safety and immunogenicity in both preclinical and clinical settings [21,22]. DCs-based vaccines show immunogenicity in the context of human papilloma virus cervical [23], ovarian cancer [24], and colorectal cancer [25,26], so they have attracted much attention. However, the antitumor efficacy of a single DC vaccine is limited.

In this study, first, we demonstrated that an induced HUVEC vaccine had a more powerful antiangiogenesis effect than a HUVEC vaccine. Based on it, an induced HUVEC vaccine was combined with a DC vaccine loading CT26 antigen. The combined vaccine examined here, targeting both tumor vascular endothelial cells and tumor cells, could be used as a new vaccine strategy for cancer therapy.

\section{Materials and Methods}

\subsection{Animals and Cell Lines}

Female BALB/c mice (4-6 weeks old) of SPF grade were purchased from Beijing Vital River Experimental Animal Center (Beijing, China) and reared in a barrier system. Primary HUVECs were obtained from the aseptic cords, which were contributed by healthy parturient donors from the Third Affiliated Hospital of Zhengzhou University. The culture methods were reported previously [27]. This study was approved by the Ethical Committee of Zhengzhou University, and all the experiments performed on mice were conducted in accordance with the guidelines set by the Animal Ethics Committee of Zhengzhou University. The murine CT26 colorectal carcinoma cell line was maintained in our laboratory and cultured in DMEM (Biological Industries, Israel) supplemented with $10 \%$ FBS. HUVECs were cultured in an endothelial cell medium (ECM) with 5\% FBS (ScienCell, Carlsbad, CA, USA). All of the cell lines were maintained at $37^{\circ} \mathrm{C}$ with $5 \% \mathrm{CO} 2$, and mycoplasma contamination was regularly analyzed in the laboratory.

\subsection{DCs Generation from Mouse Bone Marrow}

The primary bone marrow DCs were extracted from mice bone marrow precursors based on previously reported methods $[28,29]$. In brief, the tibias and femurs from 6 to 8 week-old female 
$\mathrm{BALB} / \mathrm{c}$ mice were flushed to gain bone marrow and then erythrocytes were depleted using commercial lysis buffer (Solarbio, Beijing, China). Cells were washed twice using serum-free RPMI-1640 medium (Biological Industries, Kibbutz Beit Haemek, Israel) and cultured with RPMI-1640 medium which was supplemented with $10 \%(v / v)$ FBS, $10 \mathrm{ng} \cdot \mathrm{mL}^{-1}$ recombinant murine GM-CSF (R\&D Systems, Minneapolis, MN, USA) and $10 \mathrm{ng} \cdot \mathrm{mL}^{-1}$ recombinant murine IL-4 (Peprotech, Rocky Hill, NJ, USA) in six-well plates $\left(1 \times 10^{6}\right.$ cells $\cdot \mathrm{mL}^{-1} ; 2 \mathrm{~mL} \cdot$ well $\left.{ }^{-1}\right)$ at $37^{\circ} \mathrm{C}$ with $5 \% \mathrm{CO}$. Half of the medium was updated with fresh cytokines containing rmGM-CSF and rmIL-4 without discarding any cells on days 3 and 5. On day 7, LPS (Solarbio, Beijing, China) $\left(1 \mu \mathrm{g} \cdot \mathrm{mL}^{-1}\right)$ was added to the medium. Then, DCs were prepared and then identified for use on day 8.

\subsection{Preparation of the CT26 Cell Culture Supernatant}

After reaching 70-80\% confluence, the CT26 cells were filled with $5 \mathrm{~mL}$ fresh RPMI-1640 medium containing $10 \%$ FBS. After $24 \mathrm{~h}$ of incubation, the supernatant was collected and centrifuged and then stored at $-20{ }^{\circ} \mathrm{C}$.

\subsection{Preparation of the HUVEC Vaccine}

Fixed HUVEC vaccine was prepared with $0.025 \%$ glutaraldehyde $(v / v)$. The concentration of it in PBS was adjusted to $2.5 \times 10^{7}$ cells $\cdot \mathrm{mL}^{-1}$ and then stored at $-80^{\circ} \mathrm{C}$ for injection.

\subsection{Preparation of the Induced HUVEC Vaccine}

The tumor conditioned medium (TCM) was comprised of $60 \%$ CT26 cell supernatant and $40 \%$ ECM (with 2\% FBS in the medium, without growth factors and double antibiotics). For the induced HUVEC group, after reaching 60\% confluence, HUVECs were induced by the foregoing TCM for $48 \mathrm{~h}$. A fixed induced HUVEC vaccine was prepared with $0.025 \%$ glutaraldehyde $(v / v)$. The concentration of it in PBS was adjusted to $2.5 \times 10^{7}$ cells $\cdot \mathrm{mL}^{-1}$ and then it was stored at $-80{ }^{\circ} \mathrm{C}$ for injection.

\subsection{Preparation of the DC-CT26 Vaccine}

The CT26 cells were washed twice in PBS carefully and detached with a cell scraper, and then collected in EP tubes. After centrifuging at $530 \times g$ for $5 \mathrm{~min}$ at $4{ }^{\circ} \mathrm{C}$ and discarding the supernatant, the cells were resuspended in PBS to adjust the concentration to $1 \times 10^{7}$ cells $\cdot \mathrm{mL}^{-1}$. The cells were then encapsulated in cryopreservation tubes. The cell suspensions were centrifuged at $97 \times g$ for $10 \mathrm{~min}$ at $4{ }^{\circ} \mathrm{C}$ and filtered through a $0.22 \mu \mathrm{m}$ filter after they were frozen in liquid nitrogen and disrupted by four freeze-thaw cycles. The supernatant was used as a CT26 freeze-thaw whole antigen. The CT26 cell lysate was removed from the $-80^{\circ} \mathrm{C}$ freezer and placed at $37^{\circ} \mathrm{C}$ for thawing. On the 5 th day of DC culture, the CT26 cell lysate $\left(100 \mu \mathrm{g} \cdot \mathrm{mL}^{-1}\right)$ was added to the culture medium. Then, the DC-CT26 vaccine was collected and prepared for immunization.

\subsection{Vaccination Protocols in Tumor Models}

Thirty or forty female BALB/c mice (4-6 weeks old) of SPF grade were randomly divided into three or four groups. In the armpit lymph node area, all mice were immunized with the corresponding vaccine weekly for five consecutive weeks. No blinding was done for the animal studies. Mice were injected with $1 \times 10^{5} \mathrm{CT} 26$ tumor cells subcutaneously in their left flank after the last immunization 1 week. When the subcutaneous tumors became palpable, tumor growth was measured every other day. Using the formula $\mathrm{V}=0.5 \mathrm{ab}^{2}$, the volume was computed with "a" as the long diameter in millimeters and " $b$ " as the short diameter in millimeters. The spleen tissues of mice in each group were peeled, then weighed and photographed. To examine immune function of the body, the spleen index was calculated. 
The tumor inhibition rate was computed according to the following formula:

Tumor Inhibition Rate $=($ Average Tumor Weight in the Control Group - Average Tumor Weight in the Experimental Group) / Average Tumor Weight in the Control Group $\times 100 \%$

\subsection{Wound-Healing Assay}

HUVEC s were cultured in different concentrations $(0 \%, 40 \%$, and $60 \%)$ of TCM at $37{ }^{\circ} \mathrm{C}$ and $5 \%$ $\mathrm{CO} 2$ for $48 \mathrm{~h}$. Then, they were seeded in 12-well plates and cultured overnight. After reaching about $90 \%$ confluence, the cell monolayer was scratched carefully with a $200 \mu \mathrm{L}$ pipette tip and then a straight wound was drawn in each well. Each well was washed twice with PBS. At specific time points $(0,24$, and $48 \mathrm{~h}$ ), the injured areas were captured with a microscope (Olympus, Tokyo, Japan). The number of migrated cells per field of each group was counted.

\subsection{Transwell Assay}

Precoating with diluted Matrigel (1:4; BD Biosciences, San Jose, CA, USA) in the membrane surfaces, transwell chambers (pore size: $8 \mu \mathrm{m}$; Corning, NY, USA) were incubated for $2 \mathrm{~h}$ at $37^{\circ} \mathrm{C}$. HUVECs without serum were plated onto the upper chamber, and the lower chamber was full of a complete endothelial cell medium. After that, the chambers were cultured for $24 \mathrm{~h}$ at $37^{\circ} \mathrm{C}$. The invaded cells were fixed with $10 \%$ TCA for $1 \mathrm{~h}$ and stained with crystal violet for $0.5 \mathrm{~h}$. At last, cells were captured using an inverted microscope $(\times 200)$ (Olympus, Tokyo, Japan) and counted.

\subsection{Immunohistochemistry and HEE Staining}

Tumor microvessel density was detected by immunostaining with CD31 (ab28364; 1:200; Abcam, Cambridge, UK.). The tumor tissues of each group were fixed with $10 \%$ formalin immediately after exsection. Paraffin embedding was performed, and then the tissues were cut into $4 \mu \mathrm{m}$ slices. Primary antibody was added to incubate with the paraffin slices of tumor tissues at $4{ }^{\circ} \mathrm{C}$ overnight. Under high-power fields $(\times 100)$, the mean microvessel density (MVD) for six fields was counted to show the number of vessels. In correspondence with standard histological procedures, the tumor sections were stained with hematoxylin-eosin (H\&E). The results were imaged using the optical microscope.

\subsection{Detection of the Anti-Induced HUVEC Membrane Protein Antibody by ELISA}

With a Membrane and Cytosol Protein Extraction Kit (Beyotime, Shanghai, China), induced HUVEC membrane protein was derived following the manufacturer's instructions. The protein was diluted in $0.05 \mathrm{mM}$ carbonate-bicarbonate buffer $(\mathrm{pH}=9.6)$, then applied to ELISA plates (JetBioFil, Guangzhou, China) at $100 \mu \mathrm{L}$ per well $\left(70 \mu \mathrm{g} \cdot \mathrm{mL}^{-1}\right)$ overnight at $4{ }^{\circ} \mathrm{C}$. After being washed and blocked, the plates were incubated with mice serum samples of each group at a $1: 20$ dilution at $37^{\circ} \mathrm{C}$ for $1 \mathrm{~h}$. Once the incubation with HRP-conjugated rabbit anti-mouse IgG at $37^{\circ} \mathrm{C}$ for $30 \mathrm{~min}$ was completed, the reaction was finished using TMB (Solarbio, Beijing, China) and stopped with $\mathrm{H} 2 \mathrm{SO} 4\left(2 \mathrm{~mol} \cdot \mathrm{L}^{-1}\right)$. Using an ELISA plate reader (Thermo Scientific, Waltham, MA, USA), the OD $450 \mathrm{~nm}$ values were detected. Each sample in the assay was implemented in triplicate.

\subsection{Hemoglobin Assay}

All the blood vessel formation of tumors was measured. In brief, Drabkin's reagent (Sigma-Aldrich, Inc., St. Louis, Missouri, USA) was applied to examine the content of hemoglobin in the invaded vessels in line with the manufacturer's instructions. After weighing and homogenizing the tumor tissue in $1 \mathrm{~mL}$ Drabkin reagent and centrifuging for $20 \mathrm{~min}$ at $12,000 \times g$, the supernatant was filtered through a $0.22 \mu \mathrm{m}$ Millipore filter. Using an ELISA plate reader (Thermo Scientific), the absorbance at $540 \mathrm{~nm}$ was detected to test the hemoglobin concentration of samples. The results of the experimental groups were compared with the control group. 


\subsection{Western Blot}

Protein extracts were prepared using lysis buffer for Western blot. A BCA protein assay kit (Beyotime, Shanghai, China) was implemented to detect the protein concentration. Equal amounts of the supernatant protein $(50 \mu \mathrm{g})$ were separately subjected to 10\% SDS-PAGE and transferred onto a PVDF membrane (Bio-Rad, Hercules, CA, USA). Primary antibodies were incubated overnight at $4{ }^{\circ} \mathrm{C}$ with polyclonal antibodies against VEGFR2, TEM1, TEM8, and $\beta$-actin. Antibodies against TEM1 (sc-377221; 1:250) and $\beta$-actin (sc-8432; 1:1000) were gained from Santa Cruz Biotechnology (Santa Cruz, Dallas, TX, USA). Antibodies against TEM8 (ab21269; 1:250) and VEGFR2 (ab5473; 1:250) were purchased from Abcam (Cambridge, UK). After hybridization with a horseradish peroxidase-conjugated secondary antibody, blots were visualized using a chemiluminescence detection kit (Beyotime, Shanghai, China).

\subsection{Flow Cytometry}

To detect the $\mathrm{CD} 3^{+} \mathrm{CD} 8^{+} \mathrm{T}$ lymphocytes produced by the spleen and infiltrated in the tumor tissues, $\mathrm{T}$ lymphocytes were harvested from immunized mice. After the lysis of erythrocyte and passage through a $70 \mu \mathrm{m}$ filter, the purified splenic T cells $\left(5 \times 10^{6}\right.$ cells $\left.\cdot \mathrm{mL}^{-1}\right)$ were labeled with FITC-labeled anti-CD3e (Clone 145-2C11, Biolegend, San Diego, CA, USA) and PE-labeled anti-CD8a (Clone 53-6.7; Biolegend, San Diego, CA, USA) for $60 \mathrm{~min}$ at room temperature. After washing twice with PBS and resuspending in $1 \mathrm{~mL}$ PBS with $10 \%$ FBS, the stained cells were analyzed by flow cytometry (FCM). The number of $\mathrm{CD}^{+} \mathrm{CD}^{+} \mathrm{T}$ cells was then quantified using a FACSCalibur with CellQuest software version 5.1 (BD Biosciences, Franklin Lakes, NJ, USA).

\subsection{Measurement of Cytokines}

To detect the concentration of IFN- $\gamma$, blood was collected in EP tubes and placed for $2 \mathrm{~h}$ at room temperature, then stored for $15 \mathrm{~h}$ at $4{ }^{\circ} \mathrm{C}$. The serum samples were centrifuged at $1000 \times g$ at $4{ }^{\circ} \mathrm{C}$ for $5 \mathrm{~min}$. The concentration of IFN- $\gamma$ in the supernatant was detected using commercially available ELISA kits (ExCell Biotech (Taicang) Co., Ltd, China) in correspondence with the manufacturer's directions.

\subsection{Cytotoxic T-Lymphocyte (CTL) Killing Assay}

Following the manufacturer's instructions, CTL assay against CT26 cells was implemented with a CytoTox 96 Non-Radioactive Cytotoxicity Assay kit (Promega, Madison, WI, USA). Briefly, spleen T lymphocytes were isolated from mice of each group by Mouse Spleen Lymphocyte Separation Kit (Solarbio, Beijing, China) after being sacrificed. The T lymphocytes were applied as effectors to be incubated with CT26 cells in a 96-well plate at a 50:1 ratio of effectors for $4 \mathrm{~h}$, and then the absorbance values were detected at $492 \mathrm{~nm}$. At last, the percentage of lysis efficiency was calculated in line with the following formula:

The Percentage of Lysis Efficiency $=($ Experimental Release - Effectors Spontaneous Release - Target Spontaneous Release)/(Target Maximal Release - Target Spontaneous Release) $\times 100 \%$

\subsection{Statistical Data Analysis}

Data were shown as the mean \pm SD. In this study, one-way ANOVA and least standard difference (LSD) post hoc test were applied to perform statistical analyses and significance using SPSS v17.0 (SPSS Inc., Chicago, IL, USA), when data were normally distributed. For animal studies, sample size of six mice in each group was estimated and the mice were grouped randomly to ensure power with statistical confidence. In all comparisons $p<0.05$ was deemed to be statistically significant $\left({ }^{*} p<0.05\right.$, $\left.{ }^{* *} p<0.01,{ }^{* * *} p<0.001\right)$. 


\section{Results}

3.1. HUVECs Induced by 60\% CT26 Cell Supernatant Had Characteristics Similar to Tumor Vascular Endothelial Cells

First, to simulate the tumor microenvironment, different concentrations of TCM $(0 \%, 40 \%$ and $60 \%$ CT26 cell supernatant) were applied in this study. As migration and invasion are essential for the formation of new blood vessels, wound healing and transwell assays were performed to examine the effects of the tumor microenvironment on the migration and invasion abilities of HUVECs. Notably, the results revealed that the $60 \%$ CT26 cell supernatant group had the highest number of migratory and invasive endothelial cells compared with the $0 \%$ and $40 \%$ CT26 cell supernatant groups $(p<0.001$ for both) (Figure 1A,B). Furthermore, the expression levels of tumor endothelial cell markers TEM1, TEM8, and VEGFR2 were investigated. Results revealed that the expression of all these markers was markedly higher in HUVECs after induction with the $60 \%$ CT26 cell supernatant than in the $0 \%$ CT26 cell supernatant group $(p<0.001)$ (Figure 1C).

A
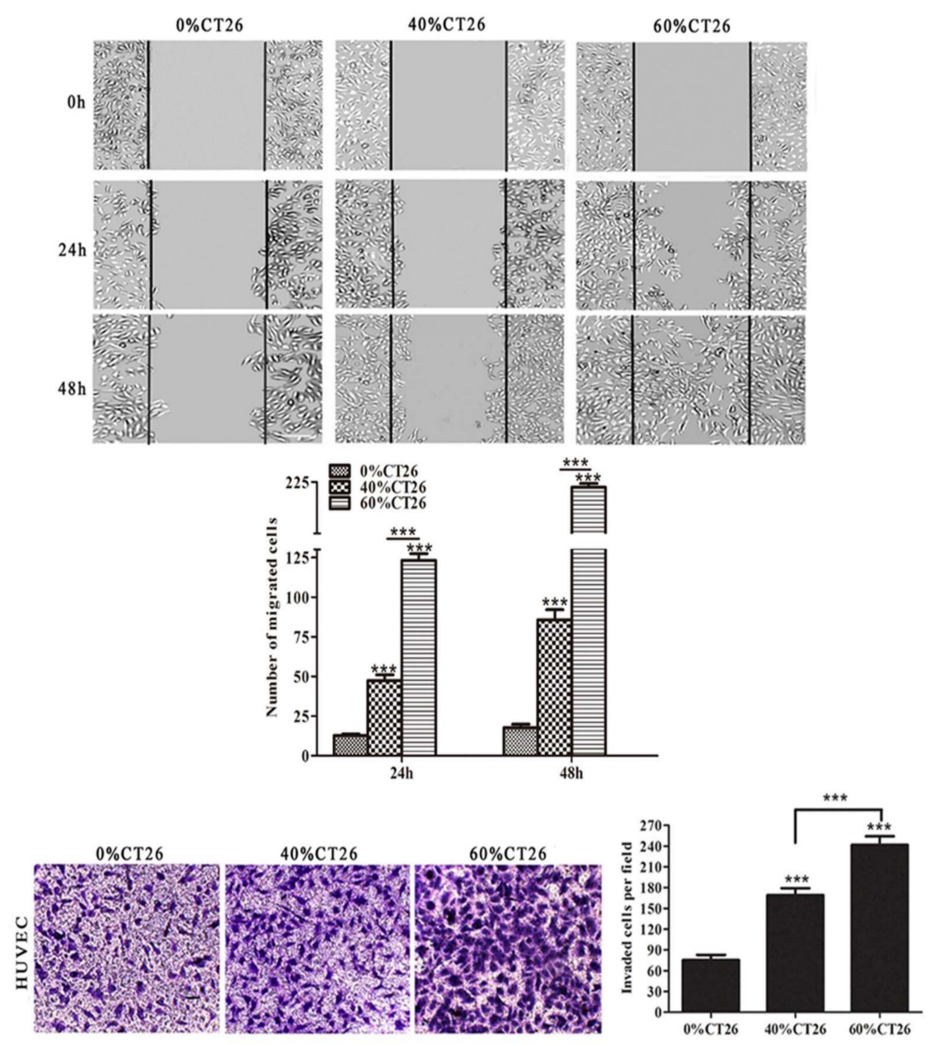

C
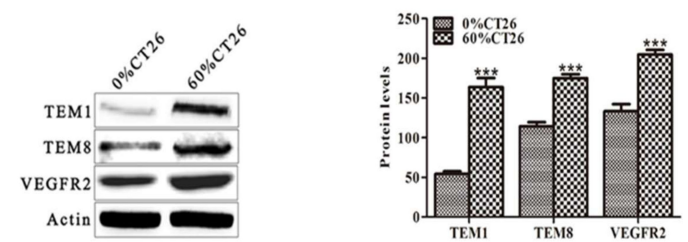

Figure 1. HUVECs induced by $60 \%$ CT26 cell supernatant enhanced the capacity of migration and invasion and highly expressed tumor vascular endothelial cell markers. (A) The wound-healing test was performed after HUVECs were induced for $48 \mathrm{~h}$ (scale bar $50 \mu \mathrm{m}$ ); (B) the transwell assay was done to examine the invasion ability of HUVECs induced by 0,40 , and $60 \%$ CT26 cell supernatant. The number of invaded cells was counted in three random fields. Representative images of invaded cells are shown (scale bar $50 \mu \mathrm{m}$ ); (C) Western blot was used to show the expression of the tumor endothelial cell markers TEM1, TEM8 and VEGFR2. Data from three independent experiments were expressed as the mean $\pm \mathrm{SD},\left({ }^{*} p<0.05 ;{ }^{* *} p<0.01 ;{ }^{* * *} p<0.001\right)$. 
Next, to exclude the influence of hormones in the serum of the colorectal carcinoma conditioned medium, certified charcoal-stripped FBS (hormone-depleted) was used to collect the colorectal carcinoma cell supernatant. The results showed that conditioned medium of human and murine colorectal cancer cells (hormone-depleted) also promoted the abilities of migration and invasion of HUVECs ( $p<0.001$ for all) (Supplementary Figures S1 and S2).

These results demonstrate that induced HUVECs have characteristics more like tumor vascular endothelial cells than HUVECs. Therefore, we hypothesized that the antitumor effect of an induced HUVEC vaccine might be better than that of a HUVEC vaccine.

\subsection{HUVEC Vaccine Induced by TCM Elicited a Better Antitumor Effect Than the HUVEC Vaccine}

Fixed xenogeneic endothelial cells have been applied as a vaccine in the immunotherapy of tumors such as lung cancer, hepatoma, and colorectal carcinoma $[8,12,30]$. To inspect the antitumor effect of HUVECs induced by TCM, we adopted the murine colorectal carcinoma animal model. After immunization, $1 \times 10^{5} \mathrm{CT} 26$ cells were injected subcutaneously into mice. Tumor dimensions were measured every other day after day 12 . The tumor volume in the induced HUVEC group was significantly lower than that in the HUVEC group $(p<0.05)$ (Figure 2A). Mice were executed on day 24, and the tumors were stripped (Figure 2B). The tumor weight in the induced HUVEC group was significantly lower than that in the HUVEC group $(p<0.05)$ (Figure 2C). Meanwhile, survival monitoring experiment showed that induced HUVEC vaccine prolonged survival of tumor-bearing mice to some extent (Figure 2D). These results suggest that HUVEC induced by TCM has a better suppressive effect on tumor growth than the HUVEC vaccine.

A

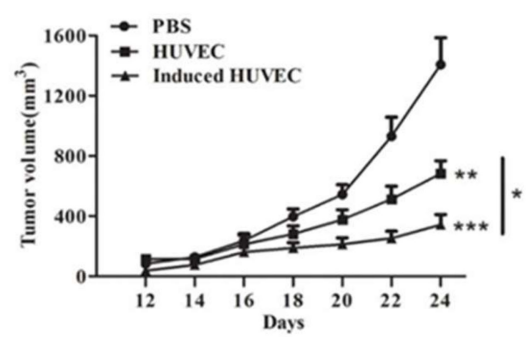

$\mathrm{C}$

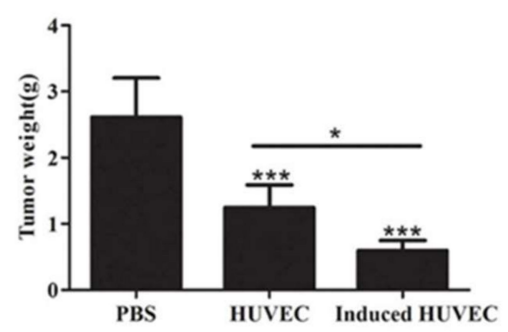

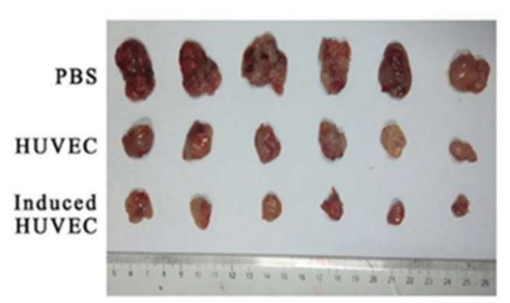

D

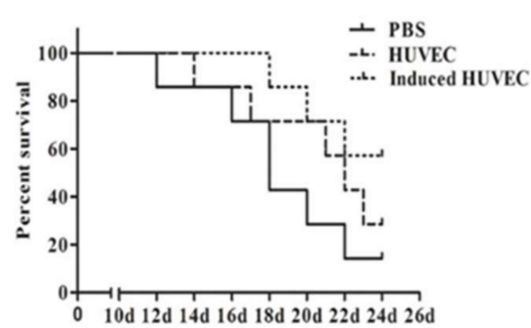

Figure 2. The TCM-induced HUVEC vaccine possessed better antitumor effects than the HUVEC vaccine. (A) Tumor growth was measured every other day after day 12; (B) tumors of each group were photographed after being stripped from mice; (C) tumor weight was tested after removal from mice.

(D) Survival data of each group was compared, $\left({ }^{*} p<0.05 ; * * p<0.01\right.$; $\left.{ }^{* * *} p<0.001\right)$.

\subsection{HUVEC Vaccine Induced by TCM Inhibited Tumor Angiogenesis}

To verify the mechanism of the better suppressive effect of the induced HUVEC vaccine, the angiogenesis status of tumor samples was investigated by immunohistochemistry. The results showed that the induced HUVEC group exhibited a significantly lower CD31-positive microvessel density in paraffin sections of tumor tissues than the PBS and HUVEC groups ( $p<0.001, p<0.01$, respectively) (Figure 3A,B). Meanwhile, the level of angiogenesis was evaluated from the hemoglobin content in the tumor tissues. The results revealed that HUVECs induced by TCM inhibited tumor angiogenesis markedly in vivo compared with PBS and HUVECs $(p<0.001, p<0.01)$ (Figure 3C). By detecting the 
expression of tumor endothelial cell markers TEM1, TEM8, and VEGFR2, the results demonstrated that protein levels from the tumor tissues in the induced HUVEC group were significantly decreased compared with the levels from the tissues in the PBS and HUVEC groups (Figure 3D).

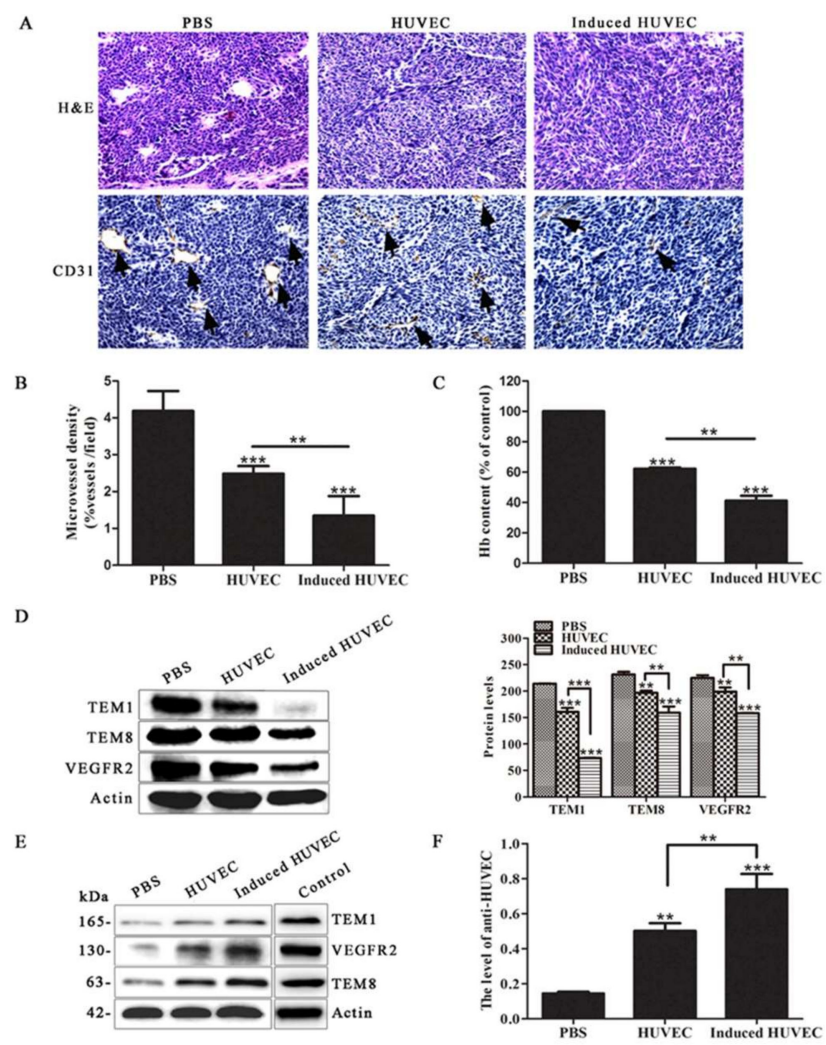

Figure 3. Induced HUVECs exerted better antiangiogenesis effects than the HUVEC vaccine. (A) H\&E staining and CD31-positive microvessels were tested by immunohistochemical staining (An arrow represented a CD31-positive microvessel); (B) vascular density was counted with CD31; (C) the hemoglobin level of the tumor tissues was examined by hemoglobin assay; (D) Western blot assay was performed to show the levels of the tumor endothelial cell markers TEM1, TEM8, and VEGFR2 in the tumor tissues; (E) a Western blot assay was performed to show the levels of anti-TEM1, anti-TEM8, and anti-VEGFR2 in mouse serum; (F) the level of the anti-induced HUVEC membrane protein antibody was checked by ELISA, $\left({ }^{*} p<0.05 ;{ }^{* *} p<0.01 ;{ }^{* * *} p<0.001\right)$.

In addition, the mouse serum of each group was extracted and applied as a primary antibody for incubation with the total protein of induced HUVECs. Because the mouse serum samples were too limited to incubate with the whole membrane, we had to cut the membrane to only check the expression of objective bands we concerned. Positive bands at the levels of 165, 130, and $63 \mathrm{kDa}$, like the bands produced by the incubation of TEM1, VEGFR2, and TEM8 antibodies with the total protein of induced HUVECs, were exhibited in the results. The positive bands were therefore presumed to be TEM1, VEGFR2, and TEM8 (Figure 3E). The testing method of anti-HUVEC antibody level induced by HUVEC vaccine and related vaccines has been reported previously [8,12,31]. In this study, the level of anti-induced HUVEC membrane protein antibody was examined by an ELISA assay. Because most of the tumor endothelial cell markers were expressed in the surface, such as TEM1, TEM8, and VEGFR2, we extracted induced HUVEC membrane protein to be coated in 96-well plates [32]. The level of the anti-induced HUVEC membrane protein antibody was examined in mouse serum. The results showed a significantly higher level in the induced HUVEC group than in the PBS and HUVEC groups (Figure 3F), which indicating that induced HUVEC vaccine can elicit a stronger antitumor effect by humoral immunity. These results reveal that immunizing mice with induced HUVECs exerts a better anti-angiogenesis effect than the HUVEC vaccine. 


\subsection{Combined Vaccine of DC-CT26 with Induced HUVECs Enhanced the Antitumor Effect}

Previous studies have shown that DC vaccines can activate $\mathrm{T}$ lymphocytes to kill tumor cells. Therefore, we expected a better antitumor effect of an induced HUVEC vaccine combined with a DC-CT26 vaccine by targeting tumor vascular endothelial cells as well as tumor cells. To test this assumption, mice were immunized with the corresponding vaccines. Results revealed that the speed of tumor growth in the combined group was slower than that in the two single-vaccine groups $(p<0.01$, $p<0.05$ ) (Figure 4A). Mice were executed on day 28, and the tumors were stripped (Figure 4B). The tumor weight showed a similar pattern ( $p<0.05$ for both) (Figure $4 C$ ). Simultaneously, the inhibition rate of tumor growth in the combined group was significantly greater than that in the DC-CT26 group and the induced HUVEC group $(p<0.001, p<0.05)$ (Figure 4D). Mice in the combined vaccine group survived longer (Figure 4E). These results imply that the combination of DC-CT26 with induced HUVECs produces a better antitumor effect than a single-component vaccine alone.

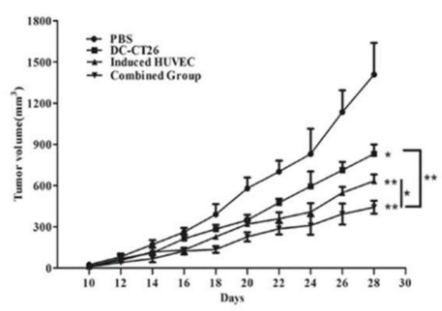

$\mathrm{C}$
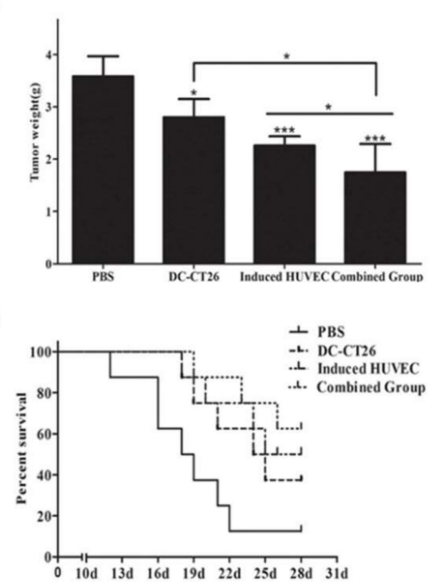

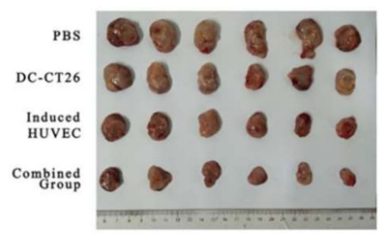

$\mathrm{D}$

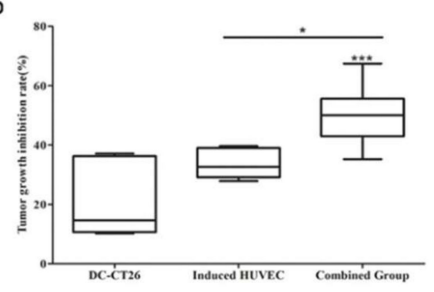

Figure 4. The combination of DC-CT26 with induced HUVECs possessed better antitumor effects than the two single-vaccine groups. (A) Tumor growth was measured every other day after day 10. (B) Tumors of each group were photographed after being stripped from mice. (C) Tumor weight was tested after removal from mice. (D) Tumor growth inhibition rate was calculated from the results of tumor weight. (E) Survival data of each group was compared, $\left({ }^{*} p<0.05\right.$; ${ }^{* *} p<0.01$; $\left.{ }^{* *} p<0.001\right)$.

3.5. Combined Vaccine of DC-CT26 and Induced HUVECs Exerted a Better Antitumor Angiogenesis Effect Than DC-CT26 or Induced HUVECs Alone

To explore the mechanism of the better effect of the combined group, the status of angiogenesis was evaluated by immunohistochemistry. The results revealed that the microvessel density of the combined group was obviously less than that of the DC-CT26 group and the induced HUVEC group $(p<0.001, p<0.01$, respectively) (Figure 5A,B). Because DCs were reported to directly interact with $\mathrm{B}$ lymphocyte to induce germinal center and antibody responses, the anti-angiogenesis effect of the combined vaccine might be promoted by the enhanced humoral immunity response [33]. By analyzing expression of the tumor vascular endothelial cell markers TEM1, TEM8, and VEGFR2 in the tumor tissues, the results demonstrated that angiogenesis in the experimental groups, especially in the combined group, was significantly lower than that in the two single-vaccine groups (Figure 5C). 


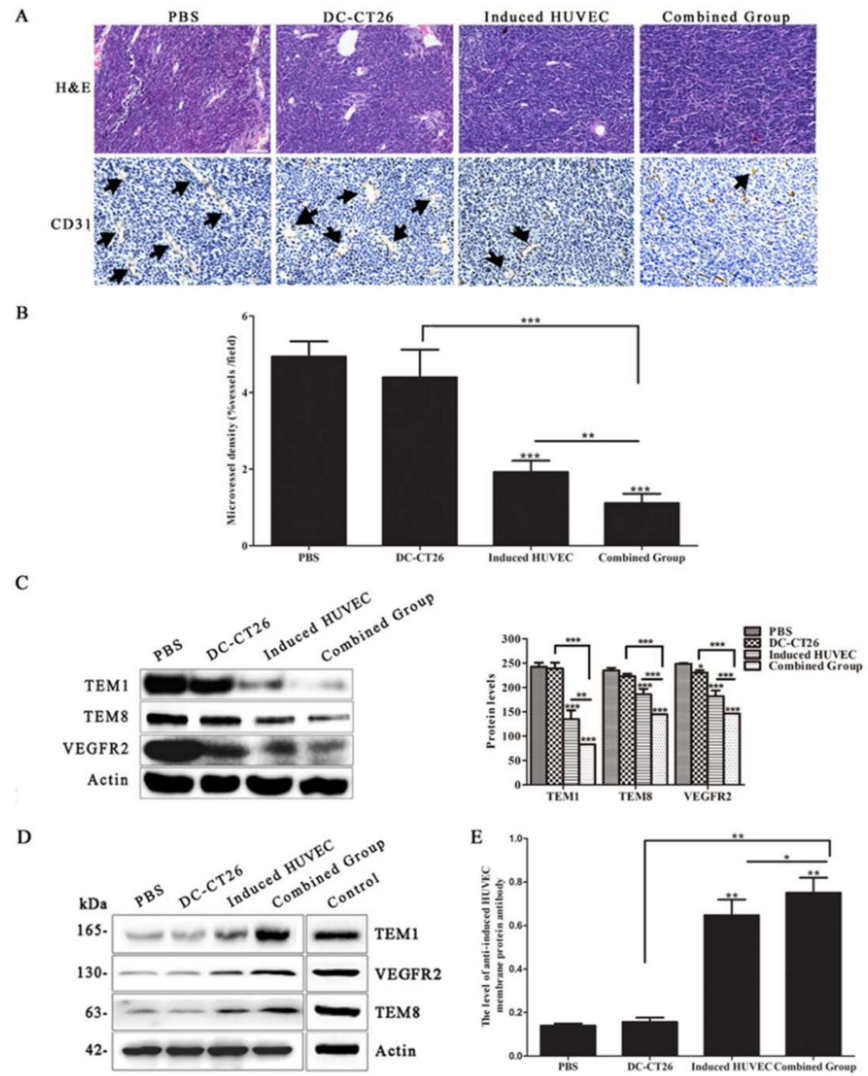

Figure 5. The combined vaccine of DC-CT26 with induced HUVECs exerted better antitumor angiogenesis effects. (A) H\&E staining and CD31-positive microvessels were tested by immunohistochemical staining; (an arrow represents a CD31-positive microvessel); (B) vascular density was counted with CD31-positive staining regions; (C) Western blot assay was performed to show the level of the tumor endothelial cell markers TEM1, TEM8, and VEGFR2 in the tumor tissues; (D) Western blot assay was performed to show the levels of anti-TEM1, anti-TEM8, and anti-VEGFR2 in mouse serum; (E) the level of anti-induced HUVEC membrane protein antibody was checked by ELISA, $\left({ }^{*} p<0.05 ;{ }^{* *} p<0.01 ;{ }^{* * *} p<0.001\right)$.

Furthermore, the mouse serum of each group was applied as a primary antibody to incubate with the total protein of induced HUVECs. Positive bands were detected at the levels of 165, 130, and $63 \mathrm{kDa}$ by western blot, like bands produced by the incubation of TEM1, VEGFR2, and TEM8 antibodies with the total protein of induced HUVECs. The positive bands were therefore presumed to be TEM1, VEGFR2, and TEM8 (Figure 5D). Meanwhile, the level of anti-induced HUVEC membrane protein antibody in mouse serum was determined by an ELISA assay. The results revealed that the level of anti-induced HUVEC membrane protein antibody in the serum was obviously higher in the combined group than in the DC-CT26 group and the induced HUVEC group $(p<0.01, p<0.05$, respectively) (Figure 5E), indicating that the DC-CT26 vaccine can enhance the humoral immunity induced by the induced HUVEC vaccine. These results suggest that immunizing mice with the combined vaccine of DC-CT26 and induced HUVECs produces a better antitumor effect than the two single-vaccine groups by suppressing angiogenesis.

\subsection{Combined Vaccine of DC-CT26 with Induced HUVECs Increased the Immune Function of the Spleen}

The spleen is well acknowledged as an important immune organ. As a proliferation site of lymphocyte, it can partly reflect the immune ability. To determine the immune function of the mice, their spleens were isolated. Measuring the spleen weight revealed that the spleen weight of the combined group was significantly heavier than that of the two single-vaccine groups $(p<0.05$ for both) (Figure 6A,B). The spleen index in the combined group was the highest compared with that 
in the DC-CT26 group and the induced HUVEC group ( $p<0.01$ for both) (Figure 6C). Meanwhile, the CTL killing assay and IFN- $\gamma$ test revealed an obviously greater cellular immune response in the combined group than in the DC-CT26 group and the induced HUVEC group ( $p<0.001$ for both) (Figure 6D,E). As is well known, CD3 molecular only exists in the surface of all T lymphocyte, while $\mathrm{CD}^{+} \mathrm{T}$ lymphocyte can directly kill tumor cells.

A

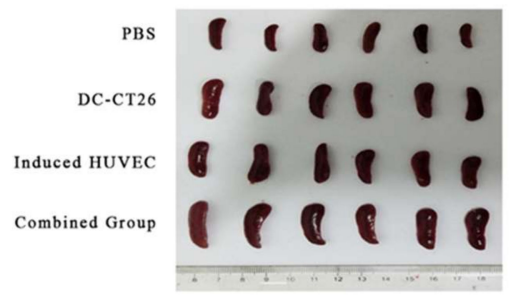

B

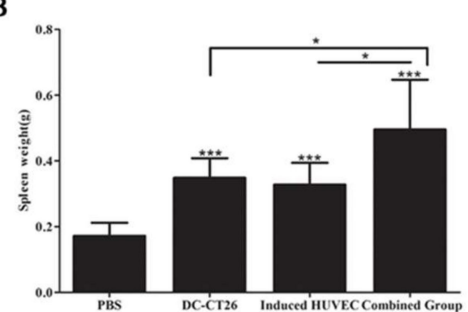

D

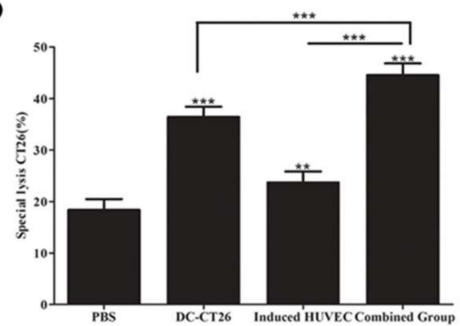

$\mathrm{F}$

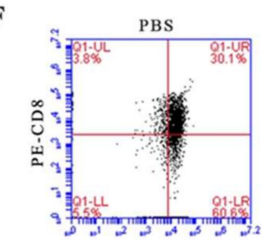

G

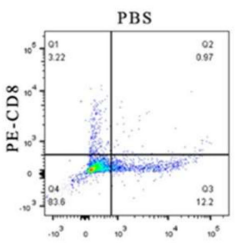

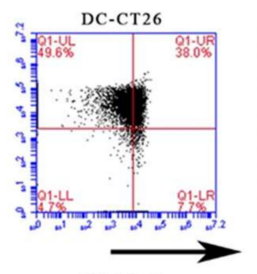

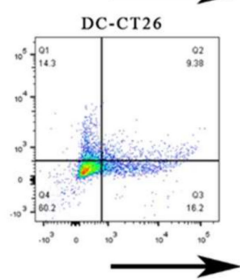

C

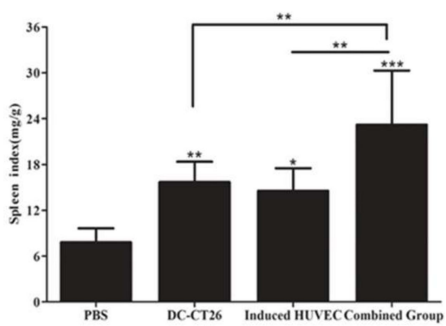

E

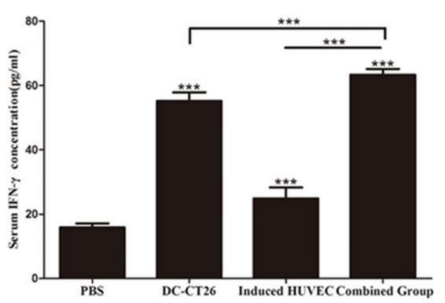

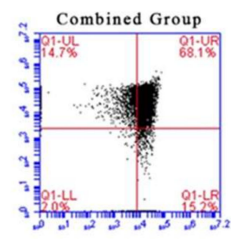

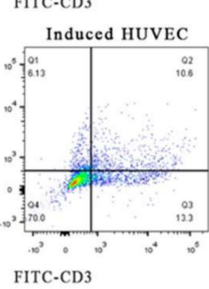

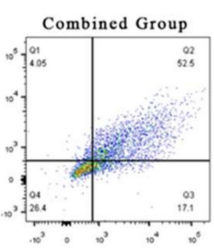

Figure 6. Immunization with DC-CT26 and induced HUVECs increased the immune function of the spleens. (A) The picture of the spleens was taken after removal from the mice; (B) the weight of the spleens was recorded; $(C)$ the spleen index was calculated; $(\mathbf{D}, \mathbf{E})$ the lysis effect of tumor-specific $\mathrm{CTL}$ and the concentration of IFN- $\gamma$ were tested; $(\mathbf{F})$ the percentage of $\mathrm{CD} 3^{+} \mathrm{CD} 8^{+} \mathrm{T}$ cells from flow cytometry represented the level of specific cellular immune response; $(\mathrm{G})$ the percentage of $\mathrm{CD} 3^{+} \mathrm{CD} 8^{+}$ $\mathrm{T}$ cells infiltrated in the tumors was detected by flow cytometry, $\left({ }^{*} p<0.05 ;{ }^{* *} p<0.01 ;{ }^{* * *} p<0.001\right)$.

In this study, firstly, flow cytometry was performed to detect the percentage of the $\mathrm{CD} 3^{+} \mathrm{CD} 8^{+} \mathrm{T}$ cells produced in the spleen. The results showed the percentage of the $\mathrm{CD} 3^{+} \mathrm{CD} 8^{+} \mathrm{T}$ cells in the spleen of combined group was more than that of the two single-vaccine groups $(p<0.001$ for both) (Figure 6F). Because of the limitation of the FACSCalibur, cells with weak fluorescence intensity cannot be shown in the figures. Thus, the values of the cell populations seem not consistent with dots density. Furtherly, 
the percentage of $\mathrm{CD}^{+} \mathrm{CD}^{+} \mathrm{T}$ cells infiltrated in tumor tissues was determined. The results showed that the percentage of $\mathrm{CD}^{+} \mathrm{CD}^{+} \mathrm{T}$ cells infiltrated in the combined group was obviously higher than that of two single-vaccine groups (Figure 6G). Taken together, these results demonstrate a significantly greater immune function of mice immunized with DC-CT26 and induced HUVECs.

\section{Discussion}

Due to the importance of tumor angiogenesis in the progression of solid tumors, vaccines with xenogeneic or syngeneic endothelial cells targeting tumor angiogenesis have been proven effective $[8,10,34]$. Immunotherapy of tumors with xenogeneic endothelial cells as a vaccine can break the body's immune tolerance to its own vascular endothelial cells, induce the immune response against its own tumor vessels, destroy the neovascularization, and inhibit the growth of tumors [7,35].

To our knowledge, this is the first study to evaluate the influence of tumor microenvironment on HUVECs in CRC. Although the HUVEC vaccine has been reported to produce a preventive antitumor microvasculature effect in several tumor models $[9,29]$, the morphology, structure, and function of normal vascular endothelial cells are different from those of tumor vascular endothelial cells [36]. Proliferating tumor endothelium highly expresses antigens, while the antigen expression level of healthy tissues is downregulated or absent on quiescent endothelium. Thus, targeting the tumor vasculature can be feasible for vaccination strategies [37]. Tumor endothelial marker (TEM) is a unique antigenic molecule in tumor vascular endothelial cells (VECs). TEM1 and TEM8 are widely expressed in the vascular system of mouse and human tumor vessels, but the expression in normal adult mouse tissues cannot be detected or can only be detected in a small number of vessels [38,39]. Here, to examine the influence of tumor microenvironment on HUVECs, the supernatant of murine CT26 colorectal cancer cells was applied to simulate the tumor microenvironment. Results showed that the migration and invasion abilities were enhanced in the induced HUVEC group, and the expression levels of TEM1 and TEM8 were also increased in the induced HUVEC group, which revealed that induced HUVECs had characteristics more like tumor vascular endothelial cells than HUVECs (Figure 1). Based on these results, we hypothesized that the antiangiogenesis effect of the induced HUVEC vaccine could be better than that of the HUVEC vaccine.

Results have shown that the induced HUVECs produced a better inhibitory effect on tumor growth and prolonged the survival of tumor-bearing mice (Figure 2). The tumor microvessel CD31 molecular marker is known to be able to accurately reflect the tumor MVD [40,41]. Moreover, the level of angiogenesis in tumor specimens can be examined by the content of hemoglobin [42]. As results showed, the induced HUVEC vaccine produced an obvious inhibition in CD31-positive microvessel density and the content of hemoglobin in tumor tissues (Figure 3A-C). These results indicated that the induced HUVEC vaccine could manifest a better antitumor effect than the HUVEC vaccine by inhibiting tumor angiogenesis. TEM1, TEM8, and VEGFR2 are specific protein molecules that are highly expressed in tumor vascular endothelial cells, promoting tumor angiogenesis [43-45]. To investigate the possible mechanism of the antiangiogenic effects of the induced HUVEC vaccine, related antibodies were detected in the serum of mice. The results showed that induced HUVECs effectively produced specific antitumor endothelial cell antibodies in vivo and caused antitumor angiogenesis through humoral immunity (Figure 3D-F). These findings suggested that the induced HUVEC vaccine represented a promising approach in the treatment of CRC.

DC vaccines have recently become a research hotspot in tumor treatment. DC vaccine loading tumor antigen can induce CTLs to kill tumor cells. The tumor cell freeze-thawed antigens contain all the tumor antigens and are widely used [46]. In the present study, murine DCs were loaded with the whole CT26 freeze-thaw antigen. Importantly, there are several advantages of the DC-CT26 vaccine. This vaccine can display all kinds of tumor antigens, stimulate the immune response against these antigens, and avoid the occurrence of immune escape.

Due to the limitations of the antitumor efficacy of the single DC vaccine, we further investigated a combination approach of the induced HUVEC vaccine with the DC-CT26 vaccine to evaluate antitumor immunity. The results supported that the effect of the combined vaccine on tumor growth was better 
than that of the single vaccine (Figure 4). Based on CD31-positive microvessel, the combined vaccine exerted a better antitumor angiogenesis effect than the single vaccine (Figure $5 \mathrm{~A}, \mathrm{~B}$ ). Because IFN- $\gamma$ can eventually inhibit tumor angiogenesis by inhibiting the proliferation of endothelial cells or indirectly downregulating the release of tumor angiogenic stimuli, mice in the combined group with large amounts of IFN- $\gamma$ in the serum showed a better antitumor effect (Figure 6E) [47-49]. To further analyze the mechanism of antitumor effects in the combined group, western blot and ELISA were performed. The results showed that the levels of specific antiangiogenic-related antibodies in the serum of the combined group were significantly higher than the levels in other groups (Figure 5D,E).

The spleen is well known to be the primary immune organ, exerting an essential role in the immunity of the host. A higher spleen index indicates a stronger immune capability [50-52]. Consistent with our findings in antitumor activity, the results showed that the spleen weight in the combined group was higher than that in the other groups (Figure 6A,B). The antitumor mechanism of the combined group was deemed to be the cytotoxic effect of the DC-CT26 vaccine on tumor cells, through inducing CTLs or IFN- $\gamma$ to kill tumor cells (Figure 6D,E). Interestingly, although the DC-CT26 had the more effective killing effect to CT26 compared with induced HUVEC vaccine in Figure 6D, the difference of their spleen weight was not obvious in 6B. We speculated that as the spleen was a proliferation site of lymphocyte, the spleen weight reflected lymphocyte proliferation capacity. Obviously, the antitumor effect of DC-CT26 was mainly performed by the T lymphocyte, while that of induced HUVEC vaccine was mainly performed by B lymphocyte. Thus, the results of the CTL killing assay, which could reflect the cellular immunity, was different between DC-CT26 vaccine and induced HUVEC vaccine. As the induced HUVEC vaccine might enhance the function of mature DCs, the mature DCs could more effectively activate the initial T cells with the formation of antigenic peptide-MHC class II molecule complexes to produce the killing effect on the target cells [33]. Therefore, the combined vaccine manufactured more $\mathrm{CD}^{+} \mathrm{CD}^{+} \mathrm{T}$ cells in the spleen (Figure $6 \mathrm{~F}$ ). Previous study has shown that severe $\mathrm{CD}^{+}$tumor infiltrating lymphocytes (TILs) processed a better prognosis compared with tumors with poor or moderate CD8 ${ }^{+}$TILs infiltration in CRC [53]. In addition, the increase of CD8 ${ }^{+}$TILs within the tumor could contribute to the inhibition of tumor growth [54]. Therefore, we investigated the percentage of $\mathrm{CD}^{+} \mathrm{CD} 8^{+} \mathrm{T}$ cells infiltrated in the tumors. Results revealed that the raising percentage of $\mathrm{CD}^{+} \mathrm{CD}^{+} \mathrm{T}$ cells infiltrated in the combined group led to a longer survival and better antitumor effect compared with the two single-vaccine groups (Figure 6G).

In conclusion, this study demonstrates that the combined vaccine containing induced HUVECs with DC-CT26 elicits strong humoral and cellular immune responses targeting both tumor angiogenesis and tumor cells. The enhanced antitumor efficacy may be attributed to synergistic mechanisms of immune responses against tumor cells as well as tumor microvasculature. As a result, tumor growth was significantly inhibited. This innovative combination of immunotherapeutic approaches may lay the foundation for the clinical treatment of related tumors and provide a new strategy for the development of vaccines against colorectal carcinoma.

Supplementary Materials: The following are available online at http://www.mdpi.com/2073-4409/8/5/494/s1, Figure S1: 60\% human colorectal carcinoma cell supernatant (hormone-depletion) enhanced the migration and invasion abilities of NECs, Figure S2: 60\% mouse colorectal carcinoma cell CT26 supernatant (hormone-depletion) enhanced the migration and invasion abilities of NECs.

Author Contributions: Conceptualization, J.L.; data curation, Q.Z., C.X. and D.W.; formal analysis, Q.Z., C.X., D.W., Y.Y. and H.L.; funding acquisition, J.L.; investigation, D.W., C.X., Q.Z., Y.Y., and H.L.; methodology, J.L., K.L., and J.Z.; project administration, J.L.; resources, K.L., J.Z., X.C., X.Z., W.Y., X.L., F.T. and Z.D.; supervision, J.L.; validation, J.L.; visualization, J.L.; writing-original draft, Q.Z., C.X. and D.W.; writing-review and editing, J.L., K.L., and J.Z.

Funding: This study was supported by grants from the Natural Science Foundation of China (no. 81572972), the Science and Technology Innovation Talents Support Plan of the University in Henan Province (no. 15HASTIT038), and the Science Foundation of Zhengzhou University for the Excellent Young Teacher (no. 1421328057).

Acknowledgments: We would like to express our thanks to Dhilli Rao Gorja for helping to polish the language of this manuscript. We thank American Journal Experts (AJE) for their professional English language editing services.

Conflicts of Interest: The authors declare no conflict of interest. 


\section{Abbreviations}

$\begin{array}{ll}\text { CRC } & \text { Colorectal carcinoma } \\ \text { CTLs } & \begin{array}{l}\text { Cytotoxic T lymphocytes } \\ \text { Dendritic cells }\end{array} \\ \text { DCs } & \begin{array}{l}\text { Induced HUVECs and dendritic cell-loading CT26 } \\ \text { antigen }\end{array} \\ \text { FCM } & \text { Flow cytometry } \\ \text { H\&E } & \text { Hematoxylin-eosin } \\ \text { HUVECs } & \text { Human umbilical vein endothelial cells } \\ \text { IFN- } \gamma & \text { Interferon- } \gamma \\ \text { LSD } & \text { Least standard difference } \\ \text { MVD } & \text { Microvessel density } \\ \text { TCM } & \text { Tumor conditioned medium } \\ \text { TEM } & \text { Tumor endothelial marker } \\ \text { VECs } & \text { Vascular endothelial cells }\end{array}$

\section{References}

1. Bray, F.; Ferlay, J.; Soerjomataram, I.; Siegel, R.L.; Torre, L.A.; Jemal, A. Global cancer statistics 2018: GLOBOCAN estimates of incidence and mortality worldwide for 36 cancers in 185 countries. CA Cancer J. Clin. 2018, 68, 394-424. [CrossRef]

2. Li, Y.; Yang, F.L.; Sang, L.X.; Zhu, J.F.; Han, X.; Shan, F.P.; Li, S.J.; Zhai, J.B.; Wang, D.N.; Lu, C.L.; et al. Enhanced therapeutic effects against murine colon carcinoma induced by a Colon 26/Ag85A-CD226 tumor cell vaccine. Oncol. Rep. 2015, 34, 1795-1804. [CrossRef] [PubMed]

3. Ebos, J.M.; Lee, C.R.; Cruz-Munoz, W.; Bjarnason, G.A.; Christensen, J.G.; Kerbel, R.S. Accelerated metastasis after short-term treatment with a potent inhibitor of tumor angiogenesis. Cancer Cell 2009, 15, 232-239. [CrossRef] [PubMed]

4. Farsaci, B.; Donahue, R.N.; Coplin, M.A.; Grenga, I.; Lepone, L.M.; Molinolo, A.A.; Hodge, J.W. Immune Consequences of Decreasing Tumor Vasculature with Antiangiogenic Tyrosine Kinase Inhibitors in Combination with Therapeutic Vaccines. Cancer Immunol. Res. 2014, 2, 1090-1102. [CrossRef] [PubMed]

5. Morera, Y.; Sanchez, J.; Bequet-Romero, M.; Selman-Housein, K.H.; de la Torre, A.; Hernandez-Bernal, F.; Martin, Y.; Garabito, A.; Pinero, J.; Bermudez, C.; et al. Specific humoral and cellular immune responses in cancer patients undergoing chronic immunization with a VEGF-based therapeutic vaccine. Vaccine 2017, 35, 3582-3590. [CrossRef] [PubMed]

6. Zhao, J.; Lu, J.; Zhou, L.; Zhao, J.; Dong, Z. Efficacy for lung metastasis induced by the allogeneic bEnd3 vaccine in mice. Hum. Vaccin. Immunother. 2018, 14, 1294-1304. [CrossRef] [PubMed]

7. Wei, Y.Q.; Wang, Q.R.; Zhao, X.; Yang, L.; Tian, L.; Lu, Y.; Kang, B.; Lu, C.J.; Huang, M.J.; Lou, Y.Y.; et al. Immunotherapy of tumors with xenogeneic endothelial cells as a vaccine. Nat. Med. 2000, 6, 1160-1166. [CrossRef] [PubMed]

8. Zhou, L.; Si, C.; Li, D.; Lu, M.; Zhong, W.; Xie, Z.; Guo, L.; Zhang, S.; Xu, M. Assessment of in vivo anti-tumor activity of human umbilical vein endothelial cell vaccines prepared by various antigen forms. Eur. J. Pharm. Sci. 2018, 114, 228-237. [CrossRef] [PubMed]

9. Chen, X.Y.; Zhang, W.; Zhang, W.; Wu, S.; Bi, F.; Su, J.J.; Tan, X.Y.; Liu, J.N.; Zhang, J. Vaccination with viable human umbilical vein endothelial cells prevents metastatic tumors by attack on tumor vasculature with both cellular and humoral immunity. Clin. Cancer Res. 2006, 12, 5834-5840. [CrossRef]

10. Liu, H.; Zhao, J.; Yang, Y.; Jin, G.; Zhang, X.; Wang, D.; Xie, C.; Liu, K.; Chen, X.; Li, X.; et al. Human umbilical vein endothelial cell vaccine suppresses the angiogenesis of esophageal squamous cell carcinoma in a humanized mouse model. Oncol. Rep. 2018, 40, 3006-3014. [CrossRef]

11. Mu, X.Y.; Fang, C.J.; Zhou, J.; Xi, Y.F.; Zhang, L.; Wei, Y.Q.; Yi, T.; Wu, Y.; Zhao, X. Fusion with human lung cancer cells elongates the life span of human umbilical endothelial cells and enhances the anti-tumor immunity. J. Cancer Res. Clin. 2016, 142, 111-123. [CrossRef] [PubMed] 
12. Xu, M.L.; Zhou, L.; Zhang, Y.L.; Xie, Z.P.; Zhang, J.; Guo, L.; Wang, C.H.; Yang, X.P. A Fixed Human Umbilical Vein Endothelial Cell Vaccine With 2 Tandem Repeats of Microbial HSP70 Peptide Epitope 407-426 As Adjuvant for Therapy of Hepatoma in Mice. J. Immunother. 2015, 38, 276-284. [CrossRef]

13. Tanaka, M.; Tsuno, N.H.; Fujii, T.; Todo, T.; Saito, N.; Takahashi, K. Human umbilical vein endothelial cell vaccine therapy in patients with recurrent glioblastoma. Cancer Sci. 2013, 104, 200-205. [CrossRef] [PubMed]

14. Ferrara, N.; Alitalo, K. Clinical applications of angiogenic growth factors and their inhibitors. Nat. Med. 1999, 5, 1359-1364. [CrossRef]

15. Balan, S.; Finnigan, J.; Bhardwaj, N. Dendritic Cell Strategies for Eliciting Mutation-Derived Tumor Antigen Responses in Patients. Cancer J. 2017, 23, 131-137. [CrossRef]

16. Zhou, J.; Xi, Y.F.; Mu, X.Y.; Zhao, R.C.; Chen, H.D.; Zhang, L.; Wu, Y.; Li, Q. Antitumor immunity induced by VE-cadherin modified DC vaccine. Oncotarget 2017, 8, 67369-67379. [CrossRef]

17. Shi, G.N.; Zhang, C.N.; Xu, R.; Niu, J.F.; Song, H.J.; Zhang, X.Y.; Wang, W.W.; Wang, Y.M.; Li, C.; Wei, X.Q.; et al. Enhanced antitumor immunity by targeting dendritic cells with tumor cell lysate-loaded chitosan nanoparticles vaccine. Biomaterials 2017, 113, 191-202. [CrossRef] [PubMed]

18. Li, C.; Liang, S.J.; Zhang, C.L.; Liu, Y.L.; Yang, M.; Zhang, J.P.; Zhi, X.; Pan, F.; Cui, D.X. Allogenic dendritic cell and tumor cell fused vaccine for targeted imaging and enhanced immunotherapeutic efficacy of gastric cancer. Biomaterials 2015, 54, 177-187. [CrossRef]

19. Garu, A.; Moku, G.; Gulla, S.K.; Chaudhuri, A. Genetic Immunization With In Vivo Dendritic Cell-targeting Liposomal DNA Vaccine Carrier Induces Long-lasting Antitumor Immune Response. Mol. Ther. 2016, 24, 385-397. [CrossRef]

20. Gordy, J.T.; Luo, K.; Francica, B.; Drake, C.; Markham, R.B. Anti-IL-10-mediated Enhancement of Antitumor Efficacy of a Dendritic Cell-targeting MIP3alpha-gp100 Vaccine in the B16F10 Mouse Melanoma Model Is Dependent on Type I Interferons. J. Immunother. 2018, 41, 181-189. [CrossRef] [PubMed]

21. Rosalia, R.A.; Quakkelaar, E.D.; Redeker, A.; Khan, S.; Camps, M.; Drijfhout, J.W.; Silva, A.L.; Jiskoot, W.; van Hall, T.; van Veelen, P.A.; et al. Dendritic cells process synthetic long peptides better than whole protein, improving antigen presentation and T-cell activation. Eur. J. Immunol. 2013, 43, 2554-2565. [CrossRef]

22. Meka, R.R.; Mukherjee, S.; Patra, C.R.; Chaudhuri, A. Shikimoyl-ligand decorated gold nanoparticles for use in ex vivo engineered dendritic cell based DNA vaccination. Nanoscale 2019, 11, 7931-7943. [CrossRef] [PubMed]

23. Kenter, G.G.; Welters, M.J.P.; Valentijn, A.R.P.M.; Lowik, M.J.G.; Berends-van der Meer, D.M.A.; Vloon, A.P.G.; Essahsah, F.; Fathers, L.M.; Offringa, R.; Drijfhout, J.W.; et al. Vaccination against HPV-16 Oncoproteins for Vulvar Intraepithelial Neoplasia. N. Engl. J. Med. 2009, 361, 1838-1847. [CrossRef]

24. Sabbatini, P.; Tsuji, T.; Ferran, L.; Ritter, E.; Sedrak, C.; Tuballes, K.; Jungbluth, A.A.; Ritter, G.; Aghajanian, C.; Bell-McGuinn, K.; et al. Phase I Trial of Overlapping Long Peptides from a Tumor Self-Antigen and Poly-ICLC Shows Rapid Induction of Integrated Immune Response in Ovarian Cancer Patients. Clin. Cancer Res. 2012, 18, 6497-6508. [CrossRef]

25. Zeestraten, E.C.M.; Speetjens, F.M.; Welters, M.J.P.; Saadatmand, S.; Stynenbosch, L.F.M.; Jongen, R.; Kapiteijn, E.; Gelderblom, H.; Nijman, H.W.; Valentijn, A.R.P.M.; et al. Addition of interferon-alpha to the p53-SLP (R) vaccine results in increased production of interferon-gamma in vaccinated colorectal cancer patients: A phase I/II clinical trial. Int. J. Cancer 2013, 132, 1581-1591. [CrossRef] [PubMed]

26. Speetjens, F.M.; Kuppen, P.K.; Welters, M.J.P.; Essahsah, F.; van den Brink, A.M.E.G.V.; Lantrua, M.G.K.; Valentijn, A.R.P.M.; Oostendorp, J.; Fathers, L.M.; Nijman, H.W.; et al. Induction of p53-Specific Immunity by a p53 Synthetic Long Peptide Vaccine in Patients Treated for Metastatic Colorectal Cancer. Clin. Cancer Res. 2009, 15, 1086-1095. [CrossRef]

27. Lu, J.; Zhao, J.; Liu, K.; Zhao, J.; Yang, H.; Huang, Y.; Qin, Z.; Bai, R.; Li, P.; Ma, J.; et al. MAPK/ERK1/2 signaling mediates endothelial-like differentiation of immature DCs in the microenvironment of esophageal squamous cell carcinoma. Cell Mol. Life Sci. 2010, 67, 2091-2106. [CrossRef] [PubMed]

28. Lutz, M.B.; Suri, R.M.; Niimi, M.; Ogilvie, A.L.; Kukutsch, N.A.; Rossner, S.; Schuler, G.; Austyn, J.M. Immature dendritic cells generated with low doses of GM-CSF in the absence of IL-4 are maturation resistant and prolong allograft survival in vivo. Eur. J. Immunol. 2000, 30, 1813-1822. [CrossRef]

29. Yang, Y.; Lu, J.; Liu, H.F.; Jin, G.G.; Bai, R.H.; Li, X.; Wang, D.Y.; Zhao, J.M.; Huang, Y.T.; Liu, K.D.; et al. Dendritic cells loading autologous tumor lysate promote tumor angiogenesis. Tumor Biol. 2016, 37, 15687-15695. [CrossRef] 
30. Okaji, Y.; Tsuno, N.H.; Kitayama, J.; Saito, S.; Takahashi, T.; Kawai, K.; Yazawa, K.; Asakage, M.; Hori, N.; Watanabe, T.; et al. Vaccination with autologous endothelium inhibits angiogenesis and metastasis of colon cancer through autoimmunity. Cancer Sci. 2004, 95, 85-90. [CrossRef]

31. Xu, M.L.; Xing, Y.; Zhou, L.; Yang, X.; Yao, W.J.; Xiao, W.; Ge, C.Y.; Ma, Y.J.; Yang, J.; Wu, J.; et al. Improved efficacy of therapeutic vaccination with viable human umbilical vein endothelial cells against murine melanoma by introduction of OK432 as adjuvant. Tumor Biol. 2013, 34, 1399-1408. [CrossRef]

32. Nanda, A.; St Croix, B. Tumor endothelial markers: New targets for cancer therapy. Curr. Opin. Oncol. 2004, 16,44-49. [CrossRef]

33. Vinuesa, C.G.; Cyster, J.G. How T Cells Earn the Follicular Rite of Passage. Immunity 2011, 35, 671-680. [CrossRef]

34. Mu, X.Y.; Sang, Y.X.; Fang, C.J.; Shao, B.; Yang, L.; Yao, K.; Zhao, X.T.; Gou, J.H.; Wei, Y.Q.; Yi, T.; et al. Immunotherapy of tumors with human telomerase reverse transcriptase immortalized human umbilical vein endothelial cells. Int. J. Oncol. 2015, 47, 1901-1911. [CrossRef]

35. Scappaticci, F.A.; Contreras, A.; Boswell, C.A.; Lewis, J.S.; Nolan, G. Polyclonal antibodies to xenogeneic endothelial cells induce apoptosis and block support of tumor growth in mice. Vaccine 2003, 21, 2667-2677. [CrossRef]

36. Jin, G.; Yang, Y.; Liu, K.; Zhao, J.; Chen, X.; Liu, H.; Bai, R.; Li, X.; Jiang, Y.; Zhang, X.; et al. Combination curcumin and (-)-epigallocatechin-3-gallate inhibits colorectal carcinoma microenvironment-induced angiogenesis by JAK/STAT3/IL-8 pathway. Oncogenesis 2017, 6. [CrossRef]

37. Wagner, S.C.; Ichim, T.E.; Ma, H.; Szymanski, J.; Perez, J.A.; Lopez, J.; Bogin, V.; Patel, A.N.; Marincola, F.M.; Kesari, S. Cancer anti-angiogenesis vaccines: Is the tumor vasculature antigenically unique? J. Transl. Med. 2015, 13, 340. [CrossRef]

38. Hida, K.; Ohga, N.; Akiyama, K.; Maishi, N.; Hida, Y. Heterogeneity of tumor endothelial cells. Cancer Sci. 2013, 104, 1391-1395. [CrossRef]

39. Carson-Walter, E.B.; Watkins, D.N.; Nanda, A.; Vogelstein, B.; Kinzler, K.W.; Croix, B.S. Cell surface tumor endothelial markers are conserved in mice and humans. Cancer Res. 2001, 61, 6649-6655.

40. Jyothsna, M.; Rammanohar, M.; Kumar, K. Histomorphometric Analysis of Angiogenesis using CD31 Immunomarker and Mast Cell Density in Oral Premalignant and Malignant Lesions: A Pilot Study. J. Clin. Diagn. Res. 2017, 11, 37-40. [CrossRef]

41. Miyata, Y.; Sagara, Y.; Watanabe, S.; Asai, A.; Matsuo, T.; Ohba, K.; Hayashi, T.; Sakai, H. CD105 is a more appropriate marker for evaluating angiogenesis in urothelial cancer of the upper urinary tract than CD31 or CD34. Virchows Arch. 2013, 463, 673-679. [CrossRef]

42. Sharma, B.; Singh, N.; Gupta, N.; Lal, P.; Pande, S.; Chauhan, S. Diagnostic Modalities of Precancerous and Cancerous Cervical Lesions with Special Emphasis on CD31 Angiogenesis Factor as a Marker. Patholog. Res. Int. 2013, 2013. [CrossRef]

43. Li, C.S.; Chacko, A.M.; Hu, J.; Hasegawa, K.; Swails, J.; Grasso, L.; El-Deiry, W.S.; Nicolaides, N.; Muzykantov, V.R.; Divgi, C.R.; et al. Antibody-based tumor vascular theranostics targeting endosialin/TEM1 in a new mouse tumor vascular model. Cancer Biol. Ther. 2014, 15, 443-451. [CrossRef] [PubMed]

44. Chaudhary, A.; Hilton, M.B.; Seaman, S.; Haines, D.C.; Stevenson, S.; Lemotte, P.K.; Tschantz, W.R.; Zhang, X.Y.M.; Saha, S.; Fleming, T.; et al. TEM8/ANTXR1 Blockade Inhibits Pathological Angiogenesis and Potentiates Tumoricidal Responses against Multiple Cancer Types. Cancer Cell 2012, 21, 212-226. [CrossRef]

45. Zafarnia, S.; Bzyl-Ibach, J.; Spivak, I.; Li, Y.P.; Koletnik, S.; Doleschel, D.; Rix, A.; Pochon, S.; Tardy, I.; Koyadan, S.; et al. Nilotinib Enhances Tumor Angiogenesis and Counteracts VEGFR2 Blockade in an Orthotopic Breast Cancer Xenograft Model with Desmoplastic Response. Neoplasia 2017, 19, 896-907. [CrossRef]

46. Chiang, C.L.; Benencia, F.; Coukos, G. Whole tumor antigen vaccines. Semin. Immunol. 2010, 22, $132-143$. [CrossRef]

47. Wallin, R.P.; Sundquist, V.S.; Brakenhielm, E.; Cao, Y.; Ljunggren, H.G.; Grandien, A. Angiostatic effects of NK cell-derived IFN-gamma counteracted by tumour cell Bcl-xL expression. Scand. J. Immunol. 2014, 79, 90-97. [CrossRef] 
48. Allen, H.; Shraga-Heled, N.; Blumenfeld, M.; Dego-Ashto, T.; Fuchs-Telem, D.; Gilert, A.; Aberman, Z.; Ofir, R. Human Placental-Derived Adherent Stromal Cells Co-Induced with TNF-alpha and IFN-gamma Inhibit Triple-Negative Breast Cancer in Nude Mouse Xenograft Models. Sci. Rep. 2018, 8, 670. [CrossRef] [PubMed]

49. George, J.; Banik, N.L.; Ray, S.K. Combination of hTERT knockdown and IFN-gamma treatment inhibited angiogenesis and tumor progression in glioblastoma. Clin. Cancer Res. 2009, 15, 7186-7195. [CrossRef]

50. Gong, Z.; Xu, H.; Su, Y.; Wu, W.; Hao, L.; Han, C. Establishment of a Novel Bladder Cancer Xenograft Model in Humanized Immunodeficient Mice. Cell Physiol. Biochem. 2015, 37, 1355-1368. [CrossRef]

51. Zhu, L.; Cao, J.; Chen, G.; Xu, Y.; Lu, J.; Fang, F.; Chen, K. Anti-tumor and immunomodulatory activities of an exopolysaccharide from Rhizopus nigricans on CT26 tumor-bearing mice. Int. Immunopharmacol. 2016, 36, 218-224. [CrossRef] [PubMed]

52. Zhou, Y.; Chen, X.; Yi, R.; Li, G.; Sun, P.; Qian, Y.; Zhao, X. Immunomodulatory Effect of Tremella Polysaccharides against Cyclophosphamide-Induced Immunosuppression in Mice. Molecules 2018, $23,239$. [CrossRef]

53. Nazemalhosseini-Mojarad, E.; Mohammadpour, S.; Torshizi Esafahani, A.; Gharib, E.; Larki, P.; Moradi, A.; Amin Porhoseingholi, M.; Asadzade Aghdaei, H.; Kuppen, P.J.K.; Zali, M.R. Intratumoral infiltrating lymphocytes correlate with improved survival in colorectal cancer patients: Independent of oncogenetic features. J. Cell Physiol. 2019, 234, 4768-4777. [CrossRef]

54. Zhang, Y.; Yang, S.L.; Zhang, H.R.; Gao, L.; Gao, X.; Liu, P.J.; Yi, Z.Y.; Li, N.; Xu, Z.Q. Combination radiotherapy and cantharidin inhibits lung cancer growth through altering tumor infiltrating lymphocytes. Future Oncol. 2017, 13, 1173-1180. [CrossRef]

(C) 2019 by the authors. Licensee MDPI, Basel, Switzerland. This article is an open access article distributed under the terms and conditions of the Creative Commons Attribution (CC BY) license (http://creativecommons.org/licenses/by/4.0/). 